\title{
Incidence of Campylobacter in slaughtered chicken
}

\section{Engy A. Hamed ${ }^{1}$, Ammar A. M. ${ }^{2}$, Mona M. Aly ${ }^{1}, \operatorname{Soad}_{\text {A. Nasef }}{ }^{1}$ and Selim A. ${ }^{1}$}

1- National Laboratory for Veterinary Quality Control on Poultry production, Animal Health Research Institute, Ministry of Agriculture, Nady El-Seid Street, Dokki P.O. Box 246, Giza 12618, Egypt

2- Microbiology Department, Faculty of Veterinary Medicine, Zagazig University, Egypt.

\begin{abstract}
A total 2565 samples (1890 samples of frozen chicken, 660 samples of freshly slaughter chicken were collected from neck skin, cloacal skin and drip and 15 samples of washing containers) from super market and slaughter poultry house in Egypt and examined for presence of Campylobacter. The Campylobacter was detected by $16.7 \%$ of all examined samples. Incidence of Campylobacter in frozen samples was $7.94 \%, 1.59 \%, 9.0 \%$ in neck skin, cloacal skin and drip respectively. The results freshly slaughter chicken of revealed $32.73 \%$ incidence of Campylobacter in samples. The incidence of Campylobacter in the examined washing water were $100 \%$. The cross contamination was occurred during the slaughter processing. And Continues test of poultry carcasses and by-product before packing and distribution is highly recommended with application of good hygienic measure importance to reduce human infection.
\end{abstract}

Key words: Campylobacter, Incidence, frozen chicken, slaughtered chicken.

\section{Introduction}

Campylobactriosis is the major important zoonotic gastrointestinal disease around the world most of cases is caused mainly by $C$. jejuni. Poultry play as an important source in transmission of that disease to human (Gormley et al, 2008). Kramer et al (2000) examined Campylobacter isolated from human and poultry samples and found the similarity in its genotypes. Most human disease caused mainly by Campylobacter jejuni but the other species may also cause the same human disease (CDC, 2013). The best suitable temperature for Campylobacter species to grow is between $37^{\circ} \mathrm{C}$ to $42^{\circ} \mathrm{C}$ and the normal body temperature of bird is $\left(41^{\circ} \mathrm{C}\right.$ to $\left.42^{\circ} \mathrm{C}\right)$ which is the same temperature whish suitable for grow of Campylobacter so bird can carry 
the campylobacter. Campylobacter bacteria cannot tolerate drying and killed by oxygen. It grow only in places with low oxygen about 5\%, number of Campylobacter in raw meat or poultry samples can decrease by freezing $(C D C, 2013)$. Campylobacter can normally colonized in the intestinal tract of poultry and are considered the most important source of infection (Lindblom and Bertil, 1995). Because of Campylobacter can colonize normally in the intestine so it can directly contaminate the meat product during evisceration inside the slaughter houses and is a major source of transmission of disease to human (Misawa et al, 1996 and Rahimi and Tajbakhsh, 2008). The most source of human infection is due to eating ready to eat food which may be in contact with the raw poultry meat, or consumption un-prober cooked poultry (Lindblom and Bertil, 1995; EFSA 2013). Small amount of bird intestinal content during slaughtering may lead to high level of contamination of poultry carcasses with Campylobacter which lead to food poisoning problems to human and applying critical control point system is recommended (Byrd et al, 1998 and Berrang et al, 2004). Freezing may reduce number of Campylobacter, so when obtained carcasses contaminated with Campylobacter to freezing point for 1-4 weeks the count is between 0.1 and $2.87 \log _{10}$ CFU/g. Campylobacter may still be present after 85 weeks of storage at $-18^{\circ} \mathrm{C}$ (EFSA, 2004). C. jejuni can be isolated from refrigerated, frozen, and combined refrigerated and frozen storage poultry samples (Bhaduri and Cottrell, 2004). Refrigeration and freezing can affect population of Campylobacter so the number of Campylobacter may be reduced upon freezing and thawing but the organism is still viable for at least one year at $18^{\circ} \mathrm{C}$ (Beuchat, 1986) When an infected bird is slaughtered, Campylobacter organis ms can be transferred from the intestines to the meat, Campylobacter was found on $47 \%$ of raw chicken samples bought in grocery stores $(C D C, 2013)$ Campylobacter has been isolated from different places of poultry processing plants and the two Campylobacter species was isolated from $32 \%$ of chicken product collected from restaurants. (Beuchat, 1986). The main objective of this study is to isolate Campylobacter from freshly slaughtered and frozen chicken

\section{Materials and Methods}

A total of 2565 samples were collected from different poultry slaughter houses from Giza government and from imported frozen broiler chicken from different supermarkets. Collected samples included skin of neck, skin around the cloaca and drip. These samples were taken from 630 frozen chicken and 220 freshly slaughtered 
chicken and 15 samples were collected from water of washing container in slaughter houses.

Isolation and identification was conducted According to ISO 10272-1:2006.

\section{Isolation}

\section{Enrichment protocols}

It was based on Bolton broth media where samples were added to $\times 9$ (weight or volume / volume) Bolton broth and incubated for 24 hours at $42^{\circ} \mathrm{C}$ in microaerophilic atmosphere.

\section{Plating}

\section{Direct plating}

Aliquot of sample was plated on two agar plats in parallel, one of which was Karmali agar and the second was CCDA agar.

Agar plates were incubated in a microaerophilic atmosphere $\left(\mathrm{CO}_{2}\right.$ $10 \%, \mathrm{O}_{2} 5 \%$ and $\mathrm{N}_{2} 85 \%$ ) at $42^{\circ} \mathrm{C}$ for $24-72 \mathrm{hrs}$.

\section{After enrichment}

After selective enrichment a loopeful of the Bolton broth was stroked on two agar plats in parallel, one of which was Karmali agar and the second was CCDA agar.

All types of agar plates were incubated in a microaerophilic atmosphere $\left(\mathrm{CO}_{2} 10 \%, \mathrm{O}_{2} 5 \%\right.$ and $\mathrm{N}_{2} 85 \%$ ) at $42^{\circ} \mathrm{C}$ or $24-72 \mathrm{hrs}$.

\section{Identification}

Colonial

morphology

Campylobacter jejuni colonies are convex metallic gray in color on Karmali agar and on CCD agar they are gray in color, moist flat spreading colonies. Campylobacter coli on Karmali agar are convex gray colonies and on CCD agar is creamy gray in color, moist and slightly raised.

Cellular morphology one colony was suspended in drop of distal water for bacterial film preparation. The film was stained with Gram stain and examined under ordinary microscope.

Biochemical reaction Oxidase test, catalas test, $\mathrm{Na}$ Hippurate hydrolysis test and Nalidixic acid and Cephalothin sensitivity test.

\section{Results}

Shape of Campylobacter cells under microscope are Gram negative, short curved rods, $\mathrm{S}$ shape or gull wings, It oxidase and catalas positive, $C$. jejuni was positive to $\mathrm{Na}$ Hippurate hydrolysis while $C$. coli and $C$. larides were negative, $C$. jejuni and C. coli were sensitive to Nalidexic acid while $C$. larides was resist to it, all thermophilic Campylobacter were sensitive to Cephalothine.

Results showed that 50 out of 630 $(7.94 \%)$ neck skin samples were positive for Campylobacter, while only 10 out of $630(1.59 \%)$ sample of cloacal skin were positive for Campylobacter High incidence (9\%) was from drip samples. 72 out of $220(32.73 \%)$ samples each of neck skin samples, cloacal skin samples, drip samples were positive. More over samples collected from water of washing container from 3 slaughters houses were $100 \%$ positive. (Table 1) 
The obtained result revealed that $40 \%$ of positive samples were $C$. jejuni and $60 \%$ was $C$. coli of neck skin samples, $0 \% \quad C$. jejuni and $100 \%$ C. coli of cloacal skin samples and $42.86 \% C$. jejuni \& $57.10 \%$ C. coli in drip samples of frozen chickens. While it was
$19.4 \%$ C. jejuni and $80.56 \%$ C. coli in neck skin, cloacal skin and drip of freshly slaughtered chickens. And the percent of isolation of Campylobacter coli in the Water from the washing container was 100\%. (Table 2, 3)

Table (1) Incidence of Campylobacter organism in frozen and fresh chicken sample

\begin{tabular}{|c|c|c|c|c|c|c|}
\hline \multicolumn{7}{|c|}{ Site of samples } \\
\hline \multicolumn{2}{|c|}{ Neck skin } & \multicolumn{2}{c|}{ Cloacal skin } & \multicolumn{2}{c|}{ Drip } & $\begin{array}{c}\text { Water from the } \\
\text { washing container }\end{array}$ \\
\hline $\begin{array}{c}\text { Frozen } \\
\text { Samples } \\
(\text { No. 630) }\end{array}$ & $\begin{array}{c}\text { Fresh } \\
\text { Samples }\end{array}$ & $\begin{array}{c}\text { Frozen } \\
\text { Samples } \\
(\text { No. 630) }\end{array}$ & $\begin{array}{c}\text { Fresh } \\
\text { Samples } \\
(\text { No. 220) }\end{array}$ & $\begin{array}{c}\text { Frozen } \\
\text { Samples } \\
(\text { No. 630) }\end{array}$ & $\begin{array}{c}\text { Fresh } \\
\text { Samples } \\
(\text { No. 220) }\end{array}$ & ( No. 15) \\
\hline $50(7.94 \%)$ & $72(32.7 \%)$ & $10(1.59 \%)$ & $72(32.7 \%)$ & $70(9 \%)$ & $72(32.7 \%)$ & $15(100 \%)$ \\
\hline
\end{tabular}

Table (2) positive samples and the percent of isolation of Campylobacter jejuni and Campylobacter coli from frozen chicken

\begin{tabular}{|c|c|c|c|c|c|}
\hline \multicolumn{3}{|c|}{ Site of samples } \\
\hline \multicolumn{2}{|c|}{$\begin{array}{c}\text { Neck skin } \\
\text { (No. 50) }\end{array}$} & \multicolumn{2}{c|}{$\begin{array}{c}\text { Cloacal skin } \\
\text { (No .10) }\end{array}$} & \multicolumn{2}{c|}{$\begin{array}{c}\text { Drip } \\
\text { ( No. 70) }\end{array}$} \\
\hline C. jejuni & C. coli & C. jejuni & C. coli & C. jejuni & C. coli \\
\hline 20 & 30 & 0 & 10 & 30 & 40 \\
\hline $40 \%$ & $60 \%$ & $0 \%$ & $100 \%$ & $42.86 \%$ & $57.10 \%$ \\
\hline
\end{tabular}

Table (3) positive samples and the percent of isolation of Campylobacter jejuni and Campylobacter coli from freshly slaughtered chicken

\begin{tabular}{|c|c|c|c|c|c|c|c|}
\hline \multicolumn{7}{|c|}{ Site of samples } \\
\hline $\begin{array}{c}\text { Neck skin } \\
\text { ( No. 72) }\end{array}$ & \multicolumn{2}{c|}{$\begin{array}{c}\text { Cloacal skin } \\
(\text { No. 72) }\end{array}$} & \multicolumn{2}{c|}{$\begin{array}{c}\text { Drip } \\
\text { (No. 72) }\end{array}$} & \multicolumn{2}{c|}{$\begin{array}{c}\text { Water from the washing } \\
\text { container }\end{array}$} \\
\hline C.jejuni & C. coli & C. jejuni & C. coli & C.jejuni & C. coli & C.jejuni & C. coli \\
\hline 14 & 58 & 14 & 58 & 14 & 58 & 0 & 15 \\
\hline $19.4 \%$ & $80.6 \%$ & $19.4 \%$ & $80.6 \%$ & $19.4 \%$ & $80.6 \%$ & $0 \%$ & $100 \%$ \\
\hline
\end{tabular}


Discussion

Campylobacter is one of the food poisoning micro-organism which causes severe cases of gastroenteritis. Poultry is the main vehicle for transmission of Campylobacter to human. The organism is commensal microorganism in intestinal tract of birds with or without any clinical signs on birds. At slaughtering of the bird the organism contaminates the water of scalding and washing containers. It was well known that the poultry carcasses was become contaminated with Campylobacter bacteria from their intestinal contents during the slaughter process (Berndeston et al, 1992). The crosscontamination of broiler carcasses by spilled gut contents at slaughter and evisceration presents a potential hygiene problem in poultry abattoirs. This may be particularly significant when Campylobacter-free flocks follow colonized flocks through the processing plant (Newell et al, 2001).

(Hafez et al, 2001) Found that in commercial poultry processing there are a several possibilities for cross contamination especially at the scalding stage. Poultry carcasses intended for sale in unfrozen form are scalded at $50.5{ }^{\circ} \mathrm{C}$ to $57{ }^{\circ} \mathrm{C}$ to safeguard the appearance of the product, but these temperatures permit pathogenic microorganism such as Campylobacter to survive in scald water and cross- contamination of many carcasses are possible.
In this study 1890 samples taken from frozen chicken were examined. Campylobacter were detected in 9\% of examined samples, this indicates that Campylobacter can survive for long period at frozen temperature and it decreases by time. (Hefnawy et al, 1989) reached to the same conclusion when examined 225 of frozen chicken and isolated the Campylobacter with percent $9.78 \%$ .The data currently available on survival of Campylobacter do not include heat resistance, although it includes information on survival at chill and freezing temperature, and at temperatures up to $42^{\circ} \mathrm{C}$. (EFSA, 2004) Mentioned that the reduction which obtained by freezing for 1-4 weeks is between 0.1 and $2.87 \log _{10}$ CFU/g. So Campylobacter may still be present after 85 weeks of storage at $-18^{\circ} \mathrm{C}$.

In this study the obtained result showed that percent of isolation of Campylobacter bacteria in the fresh slaughter chicken higher than the isolation from the frozen chicken with incidence $32.73 \%$ and $9 \%$ respectively. Ali (1992) reached to the same results of isolation of Campylobacter from drip and surface swab of fresh eviscerated whole chicken carcass was higher than which isolated from frozen whole market chicken carcasses with incidence $22 \%$ and $14 \%$ respectively.

In addition, the incidence of Campylobacter from fresh slaughter chicken carcasses, drip and skin samples were the same as well as 
species which isolated from water samples, this indicate that the cross contamination is done through the washing of carcass, this agree with Berndeston et al (1992) who Reached to the same results that poultry carcasses can become contaminated with Campylobacter bacteria from their intestinal contents during the slaughter process.

In these study 15 samples from water of washing, scalding container were examined for isolation of Campylobacter bacteria, and found that all samples were positive for isolation of Campylobacter bacteria with incidence 100\%. (Rogol et al, 1984) Reached to the same results of isolation Campylobacter from all samples collected from washing container by incidence $100 \%$. However these results is differ from the finding of (Hafez et al, 2001) when examined 30 samples from scalding water for Campylobacter from 6 out 10 monitoring flocks revealed that only one sample was positive for Campylobacter bacteria from 30 samples ( $3.33 \%$ ).

The rate of isolation in this study of Campylobacter coli is higher than the isolation of Campylobacter jejuni by incidence in frozen sampled $61.5 \%$ and $38.5 \%$ respectively. And freshly slaughtered samples, $80.6 \%$ and $19.4 \%$ respectively.(Wesley et al, 2005) Reached to the same results when examined 5 flocks and found that Campylobacter coli was predominant than Campylobacter jejuni in the $5^{\text {th }}$ flock with incidence $82.35 \%$ and $17.65 \%$ respectively. In contrast Nagla Tolba (2005) was examined 300 chicken samples and isolated Campylobacter jejuni and Campylobacter coli by incidence $51.1 \%$ and $43.2 \%$ respectively. And (Weam Ibrahim, 2005) was examined 200 samples of poultry and poultry products and isolated Campylobacter jejuni and Campylobacter coli by incidence $67.3 \%$ and $18.8 \%$ respectively.

\section{Conclusion}

The Campylobacter is one important food poisoning micro-organism which transmits to human from the consumption of under cooked poultry or misses handling of poultry carcasses so from that indicate the poultry plays a main role in transmission of Campylobacter infection to human.

The cross contamination was occurred during poultry processing. The poultry carcasses can become contaminated with Campylobacter bacteria from their intestinal contents.

Continuous poultry and poultry by products evaluation and controlling the Campylobacter should be carried out through application of good hygienic measures in order to reduce the human infection.

\section{References}

Ali S. A. A. H. M. (1992): Epidemiological studies on campylobactiosis in poultry and its public health importance. Thesis of 
Veterinary Hygiene and Zoonoses for $\mathrm{Ph}$. D. degree, Faculty of Veterinary Medicine, Cairo University, Egypt.

Berndeston, E., Tivemo, M., and Engvall, A., (1992): Distribution and numbers of Campylobacter in newly slaughtered broiler chicken and hens, International journal of Food Microbiology., Vol. 15, No. (1-2), pp. 45-50, DOI: 10.1016/0168-1605(92)90134-O

Berrang, M. E., Smith, D. P., Windham,W. R. and Feldner, P.W. (2004): Effect of intestinal content contamination on broiler carcass Campylobacter counts, Journal of Food Protection, Vol. 67, No. 2, pp. 235-238

Beuchat, L. R. (1986): Methods for detection and enumerating Campylobacter jejuni and Campylobacter coli in poultry, journal of Poultry Science, Vol. 65, No.12, pp. 2192 - 2198. DOI: $10.3382 /$ ps.0652192

Bhaduri, S. and Cottrell, $B$. (2004): Survival of Cold-Stressed Campylobacter jejuni on Ground Chicken and Chicken Skin during Frozen Storage, Applied and Environmental Microbiology journal, Vol.70, No. 12, pp. 71037109.

DOI: 10.1128/AEM.70.12.71037109.2004

Byrd, J. A., Corrier, D. E., Hume, M. E., Bailey, R. H., Stanker, L. H. and Hargis, B. M. (1998): Incidence of Campylobacter in crops of preharvest market-age broiler chickens, journal of Poultry Science,
Vol. 77, No. 9, pp. 1303-1305, DOI: $10.1093 / \mathrm{ps} / 77.9 .1303$

CDC (2013): National Center for Emerging and Zoonotic infectous Diseases, Home page Campylobacter general information, http://www.cdc.gov/cdcinfo/requestform.html

EFSA journal (2004): DRAFT 13PLEN Campylobacter in animal and food stafe. http:/www.efsa.eu.int.

EFSA journal (2013): fact sheet, EFSA explains Zoonotic diseases Campylobacter, http://www.efsa.euro pa.eu/en/corporate/pub/factsheetcam pylobacter.htm.

Hafez, M. H., hroth, S., Stadler A. and Schulze D. (2001): detection of Salmonella, Campylobacter, verotoxin producing E.cloi in turkey flocks during rearing and processing. Published in Archiv für Geflügelkunde. Vol. 65, No. 3, pp. 130-135.

Hefnawy, Y., Moustafa, S. and Fathi, S. (1989): Frozen poultry as a potential source of Campylobacter, Assut Veterinary Medicine Journal, Vol. 22, No. 43, pp. 100-105.

$\begin{array}{ll}\text { Gormley, } & \text { F.J., Macrae, } \\ \text { M., Forbes, } & \text { K.J., Ogden, }\end{array}$ I.D., Dallas, J.F., Strachan, N.J. (2008): Has Retail Chicken Played a Role in the Decline of Human Campylobacteriosis?, Journal of Applied Environmental Microbiology, Vol. 74, No. 2, pp. 383-390,

DOI: 10.1128/AEM.01455-07

ISO 10272-1 (2006): Microbiology of food and animal feeding stuffs Horizontal method for the detection 
of thermotolerant Campylobacter. ISO 10272: 2006(E) International Standards Organization, Geneva.

Kramer, J.M., Frost, J.A., Bolton, F.J., Wareing, D.R., (2000): Campylobacter contamination of raw meat and poultry at retail sale: identification of multiple types and comparison with isolates from human infection. Journal of Food Protection, Vol. 63, No. 12, pp. 1654-1659

Lindblom, G. B. and Bertil, $K$. (1995): In vitro studies of Campylobacter jejuni/ coli strains from hens and humans regarding adherence invasiveness, and toxigenicity. Journal of Avian Diseases, Vol. 39, No. 4, pp. 718722.

Misawa, N., Ohnishi, T., Uchida, K., Nakai, M., Nasu, T., Itoh, K., Takahashi, E. (1996): Experimental Hepatitis induced by Campylobacter jejuni infection in Japanese Quail. Journal of Veterinary Medical Science, Vol. 58, No. 3, pp. 205-210.

Nagla Tolba, F. K. (2005): A study on Campylobacter species in chickens in El-Fayoum Governorate. Thesis for Master degree of Bacteriology, Mycology and Immunology, Faculty of Veterinary Medicine, Beni-Sufe University, Egypt.

Newell, D. G., Shreeve J. E., Toszeghy M., Domingue G., Bull
S. Humphrey T. and Mead, G. (2001): Changes in the Carriage of Campylobacter Strains by Poultry Carcasses during Processing in Abattoirs. Journal of Applied Environmental Microbiology, Vol. 67, No. 6, pp. 2636-2640.

Rahimi E. and Tajbakhsh E. (2008): Prevalence of Campylobacter species in poultry meat in the Esfahan city, Iran, Bulgarian Journal of Veterinary Medicine, Vol. 11, No. 4, pp. 257262.

Rogol, M., Sechter I., Shtark, J., Alfi, S., Greenberg, Z. and Misrachi, R. (1984): Contamination of meat and environment with Campylobacter jejuni/coli in chicken abattoir, markets and restaurants. Journal of Israel Medicine Science, Vol. 20, No. 5, pp. 476.

Weam Ibrahim, M. B. (2005): Prevalence of Campylobacter species on processed poultry and their product, Master Thesis in meat and fish hygiene Zagazig University, Faculty of Veterinary Medicine, Egypt

Wesley, I. V., Muraoka W.T., Trampel, D. W. and Hurd, H. S. (2005): Effect of Pre- slaughter Events on Prevalence of Campylobacter jejuni and Campylobacter coli in MarketWeight Turkeys. Journal of Applied Environmental Microbiology, Vol. 71, No. 6, pp. 2824-2831 